\title{
Tris(Butadiene) Compounds versus Butadiene Oligomerization in Second-Row Transition Metal Chemistry: Effects of Increased Ligand Fields
}

\author{
Yi Zhao ${ }^{1,2}$, Qun Chen ${ }^{1}$, Mingyang He ${ }^{1}$, Zhihui Zhang ${ }^{1}\left(\mathbb{D}\right.$, Xuejun Feng ${ }^{1,3, *}$, Yaoming Xie ${ }^{3} \mathbb{C}$, \\ Robert Bruce King ${ }^{3, *}$ and Henry F. Schaefer ${ }^{3}$ \\ 1 School of Petrochemical Engineering, Changzhou University, Changzhou 213164, China; \\ zhaoyi.ripp@sinopec.com (Y.Z.); chenqunjpu@yahoo.com (Q.C.); hmy@cczu.edu.cn (M.H.); \\ zhangzh@cczu.edu.cn (Z.Z.) \\ 2 Research Institute of Petroleum Processing (RIPP), SINOPEC, Beijing 100083, China \\ 3 Department of Chemistry and Center for Computational Quantum Chemistry, University of Georgia, \\ Athens, GA 30602, USA; ymxie1@yahoo.com (Y.X.); ccq@uga.edu (H.F.S.) \\ * Correspondence: xuejun-f@163.com (X.F.); rbking@uga.edu (R.B.K.)
}

\section{check for} updates

Citation: Zhao, Y.; Chen, Q.; He, M.; Zhang, Z.; Feng, X.; Xie, Y.; King, R.B.; Schaefer, H.F. Tris(Butadiene) Compounds versus Butadiene Oligomerization in Second-Row Transition Metal Chemistry: Effects of Increased Ligand Fields. Molecules 2021, 26, 2220. https://doi.org/ $10.3390 /$ molecules 26082220

Academic Editor: Athanassios C Tsipis

Received: 6 February 2021

Accepted: 1 April 2021

Published: 12 April 2021

Publisher's Note: MDPI stays neutra with regard to jurisdictional claims in published maps and institutional affiliations.

Copyright: (c) 2021 by the authors. Licensee MDPI, Basel, Switzerland. This article is an open access article distributed under the terms and conditions of the Creative Commons Attribution (CC BY) license (https:// creativecommons.org/licenses/by/ $4.0 /)$.

\begin{abstract}
The geometries, energetics, and preferred spin states of the second-row transition metal tris(butadiene) complexes $\left(\mathrm{C}_{4} \mathrm{H}_{6}\right)_{3} \mathrm{M}(\mathrm{M}=\mathrm{Zr}-\mathrm{Pd})$ and their isomers, including the experimentally known very stable molybdenum derivative $\left(\mathrm{C}_{4} \mathrm{H}_{6}\right)_{3} \mathrm{Mo}$, have been examined by density functional theory. Such low-energy structures are found to have low-spin singlet and doublet spin states in contrast to the corresponding derivatives of the first-row transition metals. The three butadiene ligands in the lowest-energy $\left(\mathrm{C}_{4} \mathrm{H}_{6}\right)_{3} \mathrm{M}$ structures of the late second-row transition metals couple to form a $\mathrm{C}_{12} \mathrm{H}_{18}$ ligand that binds to the central metal atom as a hexahapto ligand for $\mathrm{M}=\mathrm{Pd}$ but as an octahapto ligand for $\mathrm{M}=\mathrm{Rh}$ and $\mathrm{Ru}$. However, the lowest-energy $\left(\mathrm{C}_{4} \mathrm{H}_{6}\right)_{3} \mathrm{M}$ structures of the early transition metals have three separate tetrahapto butadiene ligands for $\mathrm{M}=\mathrm{Zr}, \mathrm{Nb}$, and $\mathrm{Mo}$ or two tetrahapto butadiene ligands and one dihapto butadiene ligand for $\mathrm{M}=\mathrm{T}$. The low energy of the experimentally known singlet $\left(\mathrm{C}_{4} \mathrm{H}_{6}\right)_{3}$ Mo structure contrasts with the very high energy of its experimentally unknown singlet chromium $\left(\mathrm{C}_{4} \mathrm{H}_{6}\right)_{3} \mathrm{Cr}$ analog relative to quintet $\left(\mathrm{C}_{12} \mathrm{H}_{18}\right) \mathrm{Cr}$ isomers with an open-chain $\mathrm{C}_{12} \mathrm{H}_{18}$ ligand.
\end{abstract}

Keywords: butadiene complexes; transition metals; density functional theory

\section{Introduction}

Butadiene transition metal chemistry dates back to the 1930 discovery of butadiene iron tricarbonyl by Reihlen et al. [1], its subsequent reinvestigation by Hallam and Pauson in 1958 [2] after the 1951 discovery of ferrocene [3,4], and its structural elucidation by Mills and Robinson [5] using X-ray crystallography. The next major development was the nickel-catalyzed trimerization of butadiene to give 1,5,9-cyclododecatriene. Proposed organonickel intermediates in this process include $\left(\eta^{3,2,3}-\mathrm{C}_{12} \mathrm{H}_{18}\right) \mathrm{Ni}$ with an acyclic $\mathrm{C}_{12} \mathrm{H}_{18}$ ligand and cyclo- $\left(\eta^{2,2,2}-\mathrm{C}_{12} \mathrm{H}_{18}\right) \mathrm{Ni}$ with a complexed 1,5,9-cyclododecatriene ligand (Figure 1). The latter intermediate has been structurally characterized by X-ray crystallography [6]. However, the instability of the former intermediate has precluded similar definitive structural characterization. The bonding of the central $\mathrm{C}=\mathrm{C}$ double bond of the acyclic $\mathrm{C}_{12} \mathrm{H}_{18}$ ligand to the nickel atom in the former intermediate is uncertain since our recent theoretical studies [7] suggest a $\eta^{3,3}$-hexahapto ligand rather than the originally proposed $\eta^{3,2,3}$-octahapto ligand. No stable homoleptic $\left(\mathrm{C}_{4} \mathrm{H}_{6}\right)_{n} \mathrm{Ni}(n=2,3)$ intermediates with unsubstituted separate butadiene ligands were observed in this system, even though the nickel atom in a hypothetical $\left(\mathrm{C}_{4} \mathrm{H}_{6}\right)_{2} \mathrm{Ni}$ with two tetrahapto butadiene ligands would have the favored 18-electron configuration. 

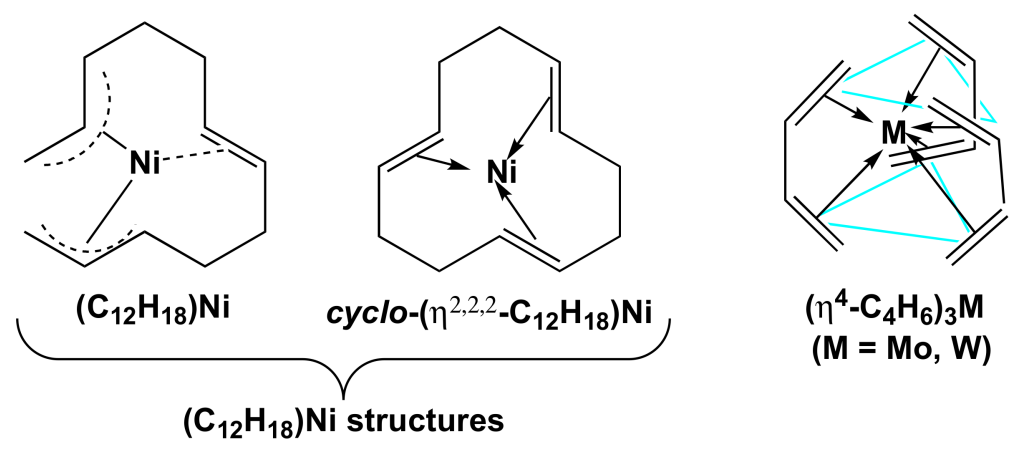

Figure 1. Comparison of the experimentally known nickel complexes with $\mathrm{C}_{12} \mathrm{H}_{18}$ ligands obtained from butadiene with the molybdenum and tungsten $\left(\mathrm{C}_{4} \mathrm{H}_{6}\right)_{3} \mathrm{M}$ complexes with three separate butadiene ligands.

Synthesis of stable homoleptic butadiene metal complexes is found to require either substituted butadienes for the first-row transition metal derivatives or the second- and third-row transition metals for stable $\left(\mathrm{C}_{4} \mathrm{H}_{6}\right)_{3} \mathrm{M}$ complexes of unsubstituted butadiene. It has been shown that 2,3-dimethylbutadiene forms an isolable crystalline homoleptic $\left(2,3-\mathrm{MeC}_{4} \mathrm{H}_{4}\right)_{2} \mathrm{Ni}$ complex which is stable only below $-10{ }^{\circ} \mathrm{C}$ [8]. Use of butadiene ligands with bulkier substituents leads to stable bis(butadiene)metal derivatives of first-row transition metals other than nickel. Thus, co-condensation of metal vapors with 1,4-bis(tertbutyl)butadiene gives corresponding [1,4- $\left.\left(\mathrm{Me}_{3} \mathrm{C}\right)_{2} \mathrm{C}_{4} \mathrm{H}_{4}\right]_{2} \mathrm{M}$ complexes $(\mathrm{M}=\mathrm{Ti}$ [9], $\mathrm{V}$ [9], Co [10]). Similarly, the zerovalent 1,4-bis(trimethylsilyl)butadiene cobalt open sandwich [1,4- $\left.\left(\mathrm{Me}_{3} \mathrm{Si}_{2}\right)_{2} \mathrm{C}_{4} \mathrm{H}_{4}\right]_{2} \mathrm{Co}$ has been synthesized and structurally characterized [11].

In contrast to the first-row transition metals, the homoleptic tris(butadiene) complexes of the second- and third-row group 6 metals molybdenum and tungsten, $\left(\eta^{4}-\mathrm{C}_{4} \mathrm{H}_{6}\right)_{3} \mathrm{M}$ $(\mathrm{M}=\mathrm{Mo}, \mathrm{W})$ are known as stable compounds. They can be synthesized by co-condensation of the metal vapors with butadiene [12] or by reduction of metal halides with activated magnesium in the presence of butadiene [13]. X-ray crystallography indicates trigonal prismatic coordination of the six $\mathrm{C}=\mathrm{C}$ double bonds of the three butadiene ligands to the central metal atom [14]. Tris(butadiene)molybdenum and related substituted butadiene derivatives have been useful precursors to the synthesis of other zerovalent molybdenum compounds such as ditertiary phosphine derivatives of the type (diene) ${ }_{2} \mathrm{Mo}$ (diphosphane) [15] and the unusual $\mathrm{Mo}\left(\mathrm{GaC}_{5} \mathrm{Me}_{5}\right)_{6}$ cluster having a central molybdenum atom surrounded by six gallium atoms with octahedral coordination [16].

Although the tris(butadiene) derivatives of the heavier group 6 transition metals molybdenum and tungsten are stable compounds, the corresponding chromium derivative $\left(\mathrm{C}_{4} \mathrm{H}_{6}\right)_{3} \mathrm{Cr}$ has never been synthesized. Furthermore, our recent theoretical studies [7] indicate that a singlet tris(butadiene)chromium structure, $\left(\eta^{4}-\mathrm{C}_{4} \mathrm{H}_{6}\right)_{3} \mathrm{Cr}$, analogous to the stable molybdenum and tungsten derivatives, is energetically disfavored relative to a quintet $\left(\eta^{3,3}-\mathrm{C}_{12} \mathrm{H}_{18}\right) \mathrm{Cr}$ structure with an open-chain bis(trihapto) $\mathrm{C}_{12} \mathrm{H}_{18}$ ligand. This observation suggests that the tris(butadiene) chemistry of the first-row transition metals is significantly different from that of their second- and third-row analogs. One factor may be the larger ligand field splitting in the second- and third-row transition metal complexes relative to their first-row transition metal analogs. An indication of this is the quintet ground state of the $\left(\mathrm{C}_{12} \mathrm{H}_{18}\right) \mathrm{Cr}$ system contrasted with the singlet state of the tris(butadiene) molybdenum and tungsten complexes.

In order to explore this matter further, we undertook density functional theory studies of the second-row transition metal butadiene complexes $\left(\mathrm{C}_{4} \mathrm{H}_{6}\right)_{3} \mathrm{M}(\mathrm{M}=\mathrm{Zr}-\mathrm{Pd})$. In general, our results confirm low-spin structures to be the lowest-energy structures for all of the second-row transition metals in accord with the larger ligand field splitting in the secondrow transition metal complexes relative to the corresponding first-row transition metal complexes. More specifically, our results confirm the experimental singlet $\left(\mathrm{C}_{4} \mathrm{H}_{6}\right)_{3} \mathrm{Mo}$ structure to be the lowest-energy isomer by a significant margin in contrast to our earlier 
studies of the $\left(\mathrm{C}_{4} \mathrm{H}_{6}\right)_{3} \mathrm{Cr}$ system. In addition, the low-energy low-spin $\left(\mathrm{C}_{4} \mathrm{H}_{6}\right)_{3} \mathrm{M}$ structures of the second-row transition metals are found to exhibit an interesting trend. Thus, in $\left(\mathrm{C}_{4} \mathrm{H}_{6}\right)_{3} \mathrm{M}$ complexes of the late transition metals requiring fewer electrons to attain the favored 18-electron configuration, the three butadiene ligands are found to couple to form a single open-chain $\mathrm{C}_{12} \mathrm{H}_{18}$ unit functioning as a hexahapto or octahapto ligand. However, for the early transition metals requiring more electrons to attain the favored 18-electron configuration, the three butadiene ligands remain as separate units thereby providing a total of 12 electrons for the central metal atom.

\section{Theoretical Methods}

Density functional theory (DFT) has been found to be a practical and effective computational tool, especially for organometallic compounds [17-23]. We used four DFT methods in this study. The first DFT method was the M06-L method, which has been claimed to be suitable for the study of organometallic and inorganic thermochemistry [24]. The second DFT method was the BP86 method, which combines Becke's 1988 exchange functional with Perdew's 1986 gradient corrected correlation functional [25,26]. Furthermore, in order to compare our current results with our earlier results on the first-row transition metal $\left(\mathrm{C}_{4} \mathrm{H}_{6}\right)_{3} \mathrm{M}$ complexes [7], we also adopted the B3LYP [27,28] and B3LYP* [29] methods in the present paper. The results show that the four DFT methods predict similar results. The B3LYP and B3LYP* results are listed in the Supplementary Materials, and the M06-L results are those mainly discussed in the text.

The Stuttgart double- $\zeta$ basis sets with an effective core potential (ECP) [30,31] were used for the second-row transition metals from zirconium to palladium. In these basis sets, 28 core electrons in the transition metal atoms are replaced by an effective core potential. This effective core approximation includes scalar relativistic contributions, which may become significant for heavy transition metal atoms. The valence basis sets are contracted from $(8 \mathrm{~s} 7 \mathrm{p} 6 \mathrm{~d})$ primitive sets to $(6 \mathrm{~s} 5 \mathrm{p} 3 \mathrm{~d})$. For the carbon and hydrogen atoms, the allelectron double- $\zeta$ plus polarization (DZP) basis sets were used. These are derived from Huzinaga and Dunning's contracted double- $\zeta$ contraction set [32] by adding spherical harmonic polarization functions with the orbital exponents $\alpha_{d}(C)=0.75$ and $\alpha_{p}(H)=0.75$. All of the computations were performed using the Gaussian 09 program [33], in which the fine grid $(75,302)$ is the default for evaluating integrals numerically [34].

The present paper discusses systems of the type $\left(\mathrm{C}_{4} \mathrm{H}_{6}\right)_{3} \mathrm{M}$, where $\mathrm{M}$ is a second-row transition metal. Thus, the $\left(\mathrm{C}_{4} \mathrm{H}_{6}\right)_{3} \mathrm{M}(\mathrm{M}=\mathrm{Zr}, \mathrm{Mo}, \mathrm{Ru}, \mathrm{Pd})$ structures were optimized in singlet and triplet electronic states and the $\left(\mathrm{C}_{4} \mathrm{H}_{6}\right)_{2} \mathrm{M}(\mathrm{M}=\mathrm{Nb}, \mathrm{Tc}, \mathrm{Rh})$-in doublet and quartet electronic states. The harmonic vibrational frequencies and the corresponding infrared intensities were determined at the same levels by evaluating force constants analytically.

The energetically low-lying $\left(\mathrm{C}_{4} \mathrm{H}_{6}\right)_{3} \mathrm{M}$ species are shown in the figures. Each structure is designated as $\mathrm{M}-\mathrm{nZ}$, where $\mathrm{M}$ is the symbol of the central metal atom, $\mathrm{n}$ orders the structure according to their relative energies predicted by the M06-L method, and $\mathrm{Z}$ designates the spin states using S, D, T, and Q for the singlet, doublet, triplet, and quartet states, respectively.

\section{Results and Discussion}

\section{1. $\left(\mathrm{C}_{4} \mathrm{H}_{6}\right)_{3} \mathrm{Pd}$}

The four lowest-energy $\left(\mathrm{C}_{4} \mathrm{H}_{6}\right)_{3} \mathrm{Pd}$ structures are all singlets with hexahapto straightchain $\mathrm{C}_{12} \mathrm{H}_{18}$ ligands of various types, leaving one uncomplexed $\mathrm{C}=\mathrm{C}$ double bond (Figure 2 and Table 1). This corresponds to a 16-electron configuration for the central palladium atom. In the lowest-energy $\left(\mathrm{C}_{4} \mathrm{H}_{6}\right)_{3} \mathrm{Pd}$ structure $\mathrm{Pd}-1 \mathrm{~S}$, the three carbon atoms at each end of the $C_{12}$ chain are bonded to the central palladium atom as trihapto allylic units leaving an uncomplexed $\mathrm{C}=\mathrm{C}$ double bond of length $1.342 \AA$ (M06-L) in the center of the chain. Structures Pd-2S and Pd-3S, lying 9.0 and $9.1 \mathrm{kcal} / \mathrm{mol}$ (M06-L), respectively, in energy above Pd-1S, have similar geometries with a hexahapto $\eta^{3,2,1}-\mathrm{C}_{12} \mathrm{H}_{18}$ ligand. In Pd-2S and Pd-3S, a terminal allylic unit, the central $\mathrm{C}=\mathrm{C}$ double bond, and an interior 
carbon atom from the other terminal allylic unit are all within bonding distance of the palladium atom. The difference between $\mathrm{Pd}-2 \mathrm{~S}$ and $\mathrm{Pd}-3 \mathrm{~S}$ is the orientation of their terminal uncomplexed $\mathrm{C}=\mathrm{C}$ double bonds. Structure $\mathrm{Pd}-4 \mathrm{~S}$, with a hexahapto $\eta^{3,2,1}-\mathrm{C}_{12} \mathrm{H}_{18}$ ligand, lies $9.5 \mathrm{kcal} / \mathrm{mol}$ in energy above Pd-1S. The hexahapto coordination includes a terminal allylic unit at one end of the $C_{12}$ chain and the carbon atom at the other end of the $C_{12}$ chain in addition to the central $\mathrm{C}=\mathrm{C}$ double bond. These four structures correspond to the four lowest-energy structures for the nickel $\left(\mathrm{C}_{4} \mathrm{H}_{6}\right)_{3} \mathrm{Ni}$ system [7] with similar relative energies (Table 1).
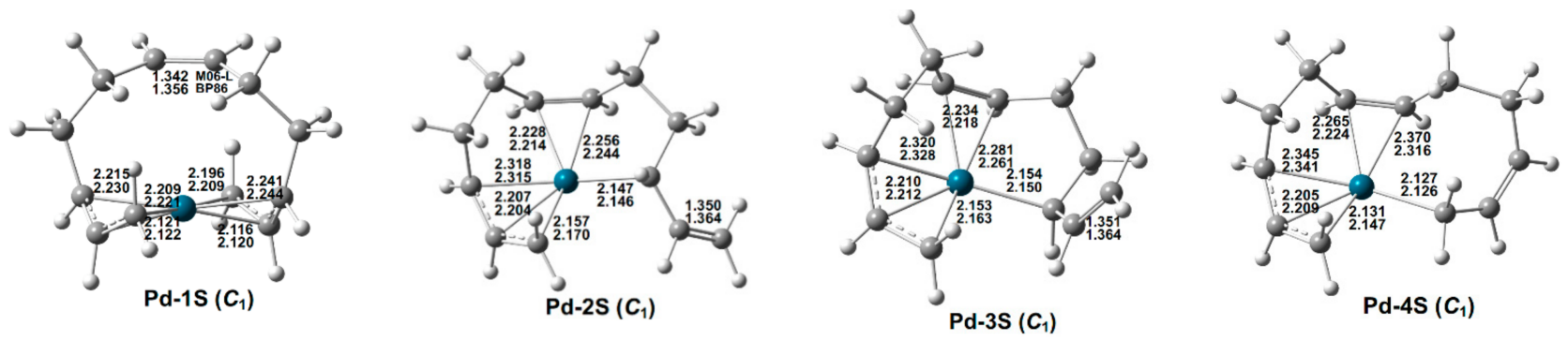

Figure 2. The optimized $\left(\mathrm{C}_{4} \mathrm{H}_{6}\right)_{3}$ Pd structures. The upper and lower distances (in $\AA$ ) are from the M06-L and BP86 methods, respectively.

Table 1. Total energies with ZPVE (zero potential vibrational energy) correction (E in hartrees), relative energies with ZPVE corrections $(\Delta \mathrm{E}$ in $\mathrm{kcal} / \mathrm{mol})$, relative enthalpies $(\Delta \mathrm{H}$ in $\mathrm{kcal} / \mathrm{mol})$, and relative free energies $\left(\Delta \mathrm{G}_{298}\right.$ in $\left.\mathrm{kcal} / \mathrm{mol}\right)$ for the $\left(\mathrm{C}_{4} \mathrm{H}_{6}\right)_{3}$ Pd structures; comparison with the $\left(\mathrm{C}_{4} \mathrm{H}_{6}\right)_{3} \mathrm{Ni}$ system [7].

\begin{tabular}{cccccc}
\hline & & Pd-1S $\left(\mathbf{C}_{\mathbf{1}}\right)$ & Pd-2S $\left(\mathbf{C}_{\mathbf{1}}\right)$ & Pd-3S $\left(\mathbf{C}_{\mathbf{1}}\right)$ & Pd-4S $\left(\mathbf{C}_{\mathbf{1}}\right)$ \\
\hline & $\mathrm{E}$ & -595.76525 & -595.75132 & -595.75118 & -595.75072 \\
M06-L & $\Delta \mathrm{E}(\Delta \mathrm{H})$ & $0.0(0.0)$ & $9.0(9.0)$ & $9.1(8.9)$ & $9.5(9.3)$ \\
& $\Delta \mathrm{G}_{298}$ & 0.0 & 8.2 & 8.9 & 9.4 \\
\hline \multirow{2}{*}{ BP86 } & $\mathrm{E}$ & -595.85507 & -595.84924 & -595.84701 & -595.84689 \\
& $\Delta \mathrm{E}(\Delta \mathrm{H})$ & $0.0(0.0)$ & $3.6(3.7)$ & $5.0(5.0)$ & $5.0(5.1)$ \\
& $\Delta \mathrm{G}_{298}$ & 0.0 & 2.8 & 4.5 & 4.7 \\
\hline$\left(\mathrm{C}_{4} \mathrm{H}_{6}\right)_{3} \mathrm{Ni}\left(\mathrm{B}_{2} \mathrm{LYP}^{*}\right)$ & $\Delta \mathrm{E}$ & 0.0 & 6.7 & 8.9 & 9.5 \\
\hline
\end{tabular}

\section{2. $\left(\mathrm{C}_{4} \mathrm{H}_{6}\right)_{3} \mathrm{Rh}$}

Four low-energy $\left(\mathrm{C}_{4} \mathrm{H}_{6}\right)_{3} \mathrm{Rh}$ doublet structures were found within $\sim 17 \mathrm{kcal} / \mathrm{mol}$ of the lowest-energy structure Rh-1D (Figure 3 and Table 2). In the two lowest-energy $\left(\mathrm{C}_{4} \mathrm{H}_{6}\right)_{3} \mathrm{Rh}$ structures Rh-1D and Rh-2D, the three butadiene ligands are coupled to form a $\mathrm{C}_{12} \mathrm{H}_{18}$ chain. Structure Rh-1D has an octahapto $\eta^{3,2,3}-\mathrm{C}_{12} \mathrm{H}_{18}$ ligand, thereby giving the central rhodium atom a 17-electron configuration. The second $\left(\mathrm{C}_{4} \mathrm{H}_{6}\right)_{3} \mathrm{Rh}$ structure Rh-2D, lying $8.9 \mathrm{kcal} / \mathrm{mol}(\mathrm{M} 06-\mathrm{L})$ in energy above Rh-1D, has a hexahapto $\eta^{3,2,1}-\mathrm{C}_{12} \mathrm{H}_{18}$ ligand with an uncomplexed $\mathrm{C}=\mathrm{C}$ double bond at the end of the $\mathrm{C}_{12} \mathrm{H}_{18}$ chain.
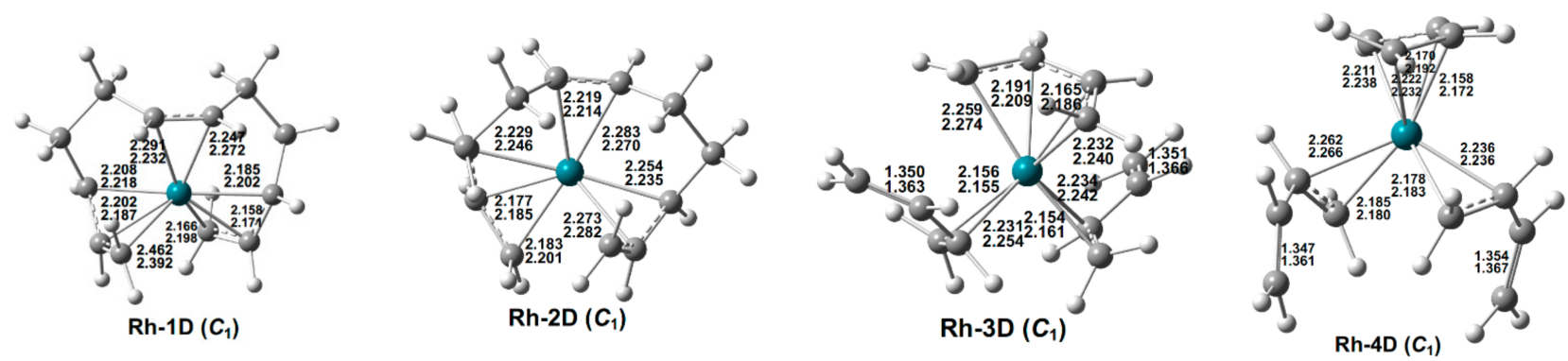

Figure 3. Optimized $\left(\mathrm{C}_{4} \mathrm{H}_{6}\right)_{3} \mathrm{Rh}$ structures. The upper and lower distances (in $\AA$ ) are from the M06-L and BP86 methods, respectively. 
Table 2. Total energies with ZPVE correction ( $\mathrm{E}$ in hartrees), relative energies with ZPVE corrections $(\Delta \mathrm{E}$ in $\mathrm{kcal} / \mathrm{mol})$, relative enthalpies $(\Delta \mathrm{H}$ in $\mathrm{kcal} / \mathrm{mol})$, and relative free energies $\left(\Delta \mathrm{G}_{298} \mathrm{in} \mathrm{kcal} / \mathrm{mol}\right)$ for the $\left(\mathrm{C}_{4} \mathrm{H}_{6}\right)_{3} \mathrm{Rh}$ structures.

\begin{tabular}{cccccc}
\hline & & Rh-1D $\left(\mathbf{C}_{\mathbf{1}}\right)$ & Rh-2D $\left(\mathbf{C}_{\mathbf{1}}\right)$ & Rh-3D $\left(\mathbf{C}_{\mathbf{1}}\right)$ & Rh-4D $\left(\mathbf{C}_{\mathbf{1}}\right)$ \\
\hline \multirow{3}{*}{ M06-L } & $\mathrm{E}$ & -578.40533 & -578.39125 & -578.38207 & -578.37905 \\
& $\Delta \mathrm{E}(\Delta \mathrm{H})$ & $0.0(0.0)$ & $8.9(8.9)$ & $14.6(16.4)$ & $16.5(18.1)$ \\
& $\Delta \mathrm{G}_{298}$ & 0.0 & 9.0 & 11.8 & 14.2 \\
\hline \multirow{3}{*}{ BP86 } & $\mathrm{E}$ & -578.52088 & -578.50221 & -578.49830 & -578.49439 \\
& $\Delta \mathrm{E}(\Delta \mathrm{H})$ & $0.0(0.0)$ & $11.6(11.8)$ & $14.1(15.8)$ & $16.5(18.2)$ \\
& $\Delta \mathrm{G}_{298}$ & 0.0 & 11.6 & 11.5 & 14.1 \\
\hline
\end{tabular}

The significantly higher-energy $\left(\mathrm{C}_{4} \mathrm{H}_{6}\right)_{3} \mathrm{Rh}$ structures Rh-3D and Rh-4D, lying 14.6 and $16.5 \mathrm{kcal} / \mathrm{mol}$ (M06-L), respectively, in energy above Rh-1D, have three separate butadiene ligands. One of these butadiene ligands is a tetrahapto ligand, whereas the two remaining butadiene ligands are dihapto ligands. Structures Rh-3D and Rh-4D differ only in the relative orientations of their terminal uncomplexed $\mathrm{C}=\mathrm{C}$ double bonds.

The previous DFT study [7] of the analogous cobalt system $\left(\mathrm{C}_{4} \mathrm{H}_{6}\right)_{3} \mathrm{Co}$ found quartet structures with the lowest-energy quartet structure lying $\sim 15 \mathrm{kcal} / \mathrm{mol}$ above the lowestenergy isomer, which is a doublet. The lowest-energy quartet structure for $\left(\mathrm{C}_{4} \mathrm{H}_{6}\right)_{3} \mathrm{Rh}$ structure is a very high-energy structure, lying more than $29 \mathrm{kcal} / \mathrm{mol}$ in energy above Rh-1D. Thus, quartet $\left(\mathrm{C}_{4} \mathrm{H}_{6}\right)_{3} \mathrm{Rh}$ structures do not appear to be chemically relevant and therefore are not discussed in detail in this paper. The high energy of the quartet $\left(\mathrm{C}_{4} \mathrm{H}_{6}\right)_{3} \mathrm{Rh}$ structures as compared with the analogous cobalt system is a consequence of the higher ligand field strengths in the second-row transition metal complexes as compared with the analogous first-row transition metal complexes.

\section{3. $\left(\mathrm{C}_{4} \mathrm{H}_{6}\right)_{3} \mathrm{Ru}$}

Four low-energy $\left(\mathrm{C}_{4} \mathrm{H}_{6}\right)_{3} \mathrm{Ru}$ structures were optimized, namely, two singlets and two triplets (Figure 4 and Table 3). The lowest-energy $\left(\mathrm{C}_{4} \mathrm{H}_{6}\right)_{3} \mathrm{Ru}$ structure $\mathrm{Ru}-1 \mathrm{~S}$ has a singlet spin state with an octahapto $\eta^{3,2,3}-\mathrm{C}_{12} \mathrm{H}_{18}$ ligand, thereby providing the ruthenium atom with a 16-electron configuration. A second singlet $\left(\mathrm{C}_{4} \mathrm{H}_{6}\right)_{3} \mathrm{Ru}$ structure $\mathrm{Ru}-2 \mathrm{~S}$, lying only $4.3 \mathrm{kcal} / \mathrm{mol}$ (M06-L) in energy above Ru-1S, has three separate butadiene ligands. Two of the butadiene ligands in Ru-2S are tetrahapto ligands, whereas the third butadiene ligand is only a dihapto ligand. This gives the central ruthenium atom the favored 18electron configuration.
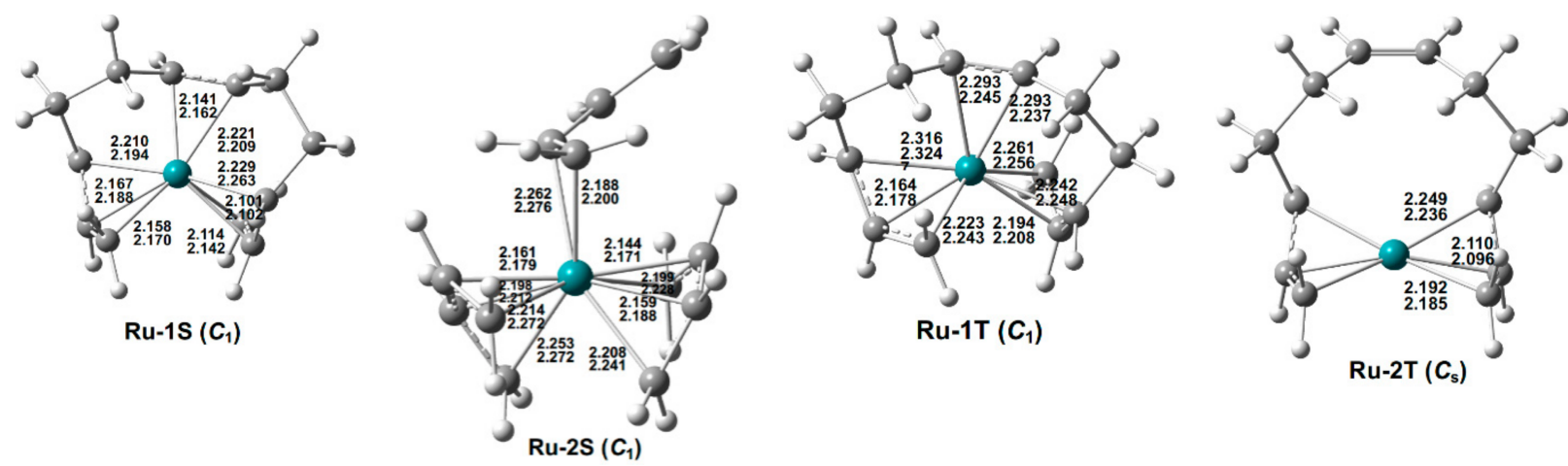

Figure 4. The optimized $\left(\mathrm{C}_{4} \mathrm{H}_{6}\right)_{3} \mathrm{Ru}$ structures. The upper and lower distances (in $\AA$ ) are from the M06-L and BP86 methods, respectively. 
Table 3. Total energies with ZPVE corrections (E in hartrees), relative energies with ZPVE corrections $(\Delta \mathrm{E}$ in $\mathrm{kcal} / \mathrm{mol})$, relative enthalpies $(\Delta \mathrm{H}$ in $\mathrm{kcal} / \mathrm{mol})$, and relative free energies $\left(\Delta \mathrm{G}_{298} \mathrm{in} \mathrm{kcal} / \mathrm{mol}\right)$ for the $\left(\mathrm{C}_{4} \mathrm{H}_{6}\right)_{3} \mathrm{Ru}$ structures; comparison with the $\left(\mathrm{C}_{4} \mathrm{H}_{6}\right)_{3} \mathrm{Fe}$ system [7].

\begin{tabular}{cccccc}
\hline & & Ru-1S $\left(\mathbf{C}_{\mathbf{1}}\right)$ & Ru-2S $\left(\mathbf{C}_{\mathbf{1}}\right)$ & Ru-1T $\left(\mathbf{C}_{\mathbf{1}}\right)$ & Ru-2T $\left(\mathbf{C}_{\mathbf{s}}\right)$ \\
\hline & $\mathrm{E}$ & -562.75206 & -562.74555 & -562.71903 & -562.72023 \\
M06-L & $\Delta \mathrm{E}(\Delta \mathrm{H})$ & $0.0(0.0)$ & $4.3(5.1)$ & $20.7(21.3)$ & $20.2(20.7)$ \\
& $\Delta \mathrm{G}_{298}$ & 0.0 & 3.4 & 19.0 & 18.0 \\
\hline \multirow{2}{*}{ BP86 } & $\mathrm{E}$ & -562.87730 & -562.86819 & -562.84327 & -562.83165 \\
& $\Delta \mathrm{E}(\Delta \mathrm{H})$ & $0.0(0.0)$ & $6.0(6.6)$ & $21.4(21.7)$ & $28.7(29.2)$ \\
& $\Delta \mathrm{G}_{298}$ & 0.0 & 5.4 & 20.7 & 26.8 \\
\hline$\left(\mathrm{C}_{4} \mathrm{H}_{6}\right)_{3} \mathrm{Fe}\left(\right.$ B3LYP $\left.^{*}\right)$ & $\Delta \mathrm{E}$ & 9.8 & 31.0 & 0.0 & 0.9 \\
\hline
\end{tabular}

The lowest-energy triplet $\left(\mathrm{C}_{4} \mathrm{H}_{6}\right)_{3} \mathrm{Ru}$ structures lie $\sim 20 \mathrm{kcal} / \mathrm{mol}$ in energy above the lowest-energy singlet structure Ru-1S (Figure 4 and Table 3 ). This contrasts with the analogous $\left(\mathrm{C}_{4} \mathrm{H}_{6}\right)_{3} \mathrm{Fe}$ system for which the lowest-energy structures are triplet spin state structures [7]. Furthermore, for $\left(\mathrm{C}_{4} \mathrm{H}_{6}\right)_{3} \mathrm{Fe}$, even a quintet structure has a lower energy than the lowest-energy singlet structure. This, again, is an example of the preference of the second-row transition metals for lower spin states relative to analogous complexes of the first-row transition metals. The triplet $\left(\mathrm{C}_{4} \mathrm{H}_{6}\right)_{3} \mathrm{Ru}$ structure $\mathrm{Ru}-1 \mathrm{~T}$ has an octahapto $\eta^{3,2,3}$. $\mathrm{C}_{12} \mathrm{H}_{18}$ ligand, thereby giving the ruthenium atom a 16-electron configuration consistent with a triplet spin state in a high-spin complex. The second triplet $\left(\mathrm{C}_{4} \mathrm{H}_{6}\right)_{3} \mathrm{Ru}$ structure Ru-2T with a similar energy as $\mathrm{Ru}-1 \mathrm{~T}$ has a hexahapto $\eta^{3,3}-\mathrm{C}_{12} \mathrm{H}_{18}$ ligand similar to that in $\mathrm{Pd}-1 \mathrm{~S}$, with an uncomplexed central $\mathrm{C}=\mathrm{C}$ double bond. This gives the ruthenium atom in Ru-2T only a 14-electron configuration, which can also be the basis for a triplet spin state structure. Note that the M06-L method predicts $\mathrm{Ru}-1 \mathrm{~T}$ and $\mathrm{Ru}-2 \mathrm{~T}$ to have essentially the same energies, while the BP86 method predicts Ru-2T to lie $\sim 7 \mathrm{kcal} / \mathrm{mol}$ in energy above Ru-1T.

\section{4. $\left(\mathrm{C}_{4} \mathrm{H}_{6}\right)_{3} \mathrm{Tc}$}

Three low-energy doublet structures were optimized for $\left(\mathrm{C}_{4} \mathrm{H}_{6}\right)_{3} \mathrm{Tc}_{\mathrm{c}}$ (Figure 5 and Table 4). Quartet and sextet $\left(\mathrm{C}_{4} \mathrm{H}_{6}\right)_{3} \mathrm{Tc}$ structures have energies at least $13 \mathrm{kcal} / \mathrm{mol}$ in energy above the lowest-energy doublet $\left(\mathrm{C}_{4} \mathrm{H}_{6}\right)_{3}$ Tc structure Tc-1D. This contrasts with the $\left(\mathrm{C}_{4} \mathrm{H}_{6}\right)_{3} \mathrm{Mn}$ system for which the lowest energy structures are sextet structures and the lowest- energy doublet structure lies $\sim 24 \mathrm{kcal} / \mathrm{mol}$ in energy above the lowest-energy sextet structure [7]. This, again, is an indication of the higher ligand field strength in the secondrow transition metals relative to analogous complexes of the first-row transition metals.

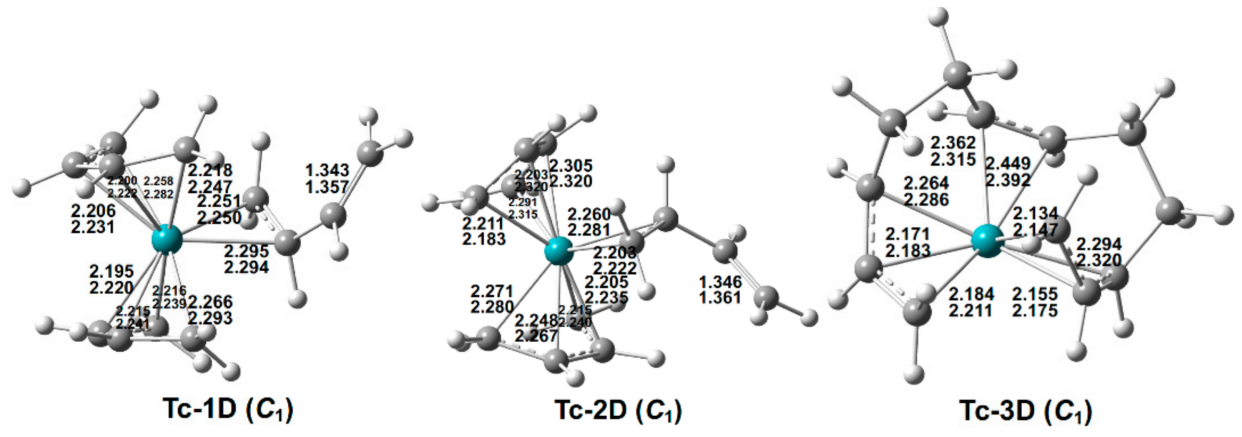

Figure 5. The optimized $\left(\mathrm{C}_{4} \mathrm{H}_{6}\right)_{3}$ Tc structures. The upper and lower distances (in $\AA$ ) are from the M06-L and BP86 methods, respectively. 
Table 4. Total energies with ZPVE corrections (E in hartrees), relative energies with ZPVE corrections $(\Delta \mathrm{E}$ in $\mathrm{kcal} / \mathrm{mol})$, relative enthalpies $(\Delta \mathrm{H}$ in $\mathrm{kcal} / \mathrm{mol})$, and relative free energies $\left(\Delta \mathrm{G}_{298} \mathrm{in} \mathrm{kcal} / \mathrm{mol}\right)$ for the $\left(\mathrm{C}_{4} \mathrm{H}_{6}\right)_{3}$ Tc structures; comparison with the $\left(\mathrm{C}_{4} \mathrm{H}_{6}\right)_{3} \mathrm{Mn}$ system [7].

\begin{tabular}{ccccc}
\hline & & Tc-1D $\left(\mathbf{C}_{\mathbf{1}}\right)$ & Tc-2D $\left(\mathbf{C}_{\mathbf{1}}\right)$ & Tc-3D $\left(\mathbf{C}_{\mathbf{1}}\right)$ \\
\hline & $\mathrm{E}$ & -548.63293 & -548.63130 & -548.61490 \\
M06-L & $\Delta \mathrm{E}(\Delta \mathrm{H})$ & $0.0(0.0)$ & $1.0(0.8)$ & $11.3(10.4)$ \\
& $\Delta \mathrm{G}_{298}$ & 0.0 & 1.3 & 12.8 \\
\hline \multirow{2}{*}{ BP86 } & $\mathrm{E}$ & -548.76092 & -548.76018 & -548.73899 \\
& $\Delta \mathrm{E}(\Delta \mathrm{H})$ & $0.0(0.0)$ & $0.5(0.3)$ & $13.8(12.4)$ \\
& $\Delta \mathrm{G}_{298}$ & 0.0 & 0.6 & 15.5 \\
\hline$\left(\mathrm{C}_{4} \mathrm{H}_{6}\right)_{3} \mathrm{Mn}\left(\mathrm{B}_{2} \mathrm{LYP}^{*}\right)$ & $\Delta \mathrm{E}$ & 23.9 & 25.9 & 27.5 \\
\hline
\end{tabular}

The lowest-energy $\left(\mathrm{C}_{4} \mathrm{H}_{6}\right)_{3} \mathrm{Tc}_{\mathrm{c}}$ structures Tc-1D and Tc-2D are almost degenerate in energy within $1.0 \mathrm{kcal} / \mathrm{mol}$ (M06-L) (Figure 5 and Table 4). Both structures have two tetrahapto butadiene ligands and one dihapto butadiene ligand with an uncomplexed $\mathrm{C}=\mathrm{C}$ double bond of length $\sim 1.35 \AA$. This arrangement of butadiene ligands gives the technetium atoms in these structures 17-electron configurations, consistent with the doublet spin state. Structures Tc-1D and Tc-2D differ only in the orientations of their butadiene ligands. The other doublet $\left(\mathrm{C}_{4} \mathrm{H}_{6}\right)_{3} \mathrm{Tc}$ structure Tc-3D, lying $11.3 \mathrm{kcal} / \mathrm{mol}(\mathrm{M} 06-\mathrm{L})$ in energy above Tc-1D, has three butadiene units coupled to form an octahapto $\eta^{3,2,3}-\mathrm{C}_{12} \mathrm{H}_{18}$ ligand, thereby giving the technetium atom a 15-electron configuration.

\section{5. $\left(\mathrm{C}_{4} \mathrm{H}_{6}\right)_{3} \mathrm{Mo}$}

Six low-energy $\left(\mathrm{C}_{4} \mathrm{H}_{6}\right)_{3}$ Mo structures were found, namely, three singlets and three triplets (Figure 6 and Table 5). The theoretical singlet structure Mo-1S is predicted to be the global minimum, and is experimentally known as a stable species [12-15]. Structure Mo-1S has three separate tetrahapto butadiene ligands, thereby giving the molybdenum atom the favored 18-electron configuration. Table 6 shows that our predicted geometric parameters agree with experiment, especially with the more reliable low-temperature $\mathrm{X}$-ray crystallographic structures in the 2002 paper [14]. For example, the predicted $\mathrm{Mo}-\mathrm{C} 1$ distances $(\sim 2.28 \AA)$ and the Mo-C2 distances $(\sim 2.35 \AA)$ agree within $0.02 \AA$. The C1-C2 distances $(\sim 1.44 \AA)$ and C2-C2A distances $(\sim 1.41 \AA)$ also agree within $0.02 \AA$. Our predicted C1-C2-C2A angle $\left(118.9^{\circ}\right.$ or $\left.119.1^{\circ}\right)$ agrees with the experimental result $\left(119.7^{\circ}\right)$ within $1^{\circ}$. Kaupp et al. also carried out a computational study on Mo-1S [14]. We found that the geometry parameters from different computational methods are in reasonable agreement (Table S8 in the Supporting Information).

Table 5. Total energies with ZPVE corrections (E in hartrees), relative energies with ZPVE corrections $(\Delta \mathrm{E}$ in $\mathrm{kcal} / \mathrm{mol})$, relative enthalpies $(\Delta \mathrm{H}$ in $\mathrm{kcal} / \mathrm{mol})$, and relative free energies $\left(\Delta \mathrm{G}_{298}\right.$ in $\left.\mathrm{kcal} / \mathrm{mol}\right)$ for the $\left(\mathrm{C}_{4} \mathrm{H}_{6}\right)_{3}$ Mo structures; comparison with the $\left(\mathrm{C}_{4} \mathrm{H}_{6}\right)_{3} \mathrm{Cr}$ system [7].

\begin{tabular}{|c|c|c|c|c|c|c|c|}
\hline & & $\operatorname{Mo-1S}\left(C_{3 h}\right)$ & $\operatorname{Mo-2S}\left(C_{1}\right)$ & $\operatorname{Mo}-3 S\left(C_{1}\right)$ & $\operatorname{Mo-1T}\left(C_{1}\right)$ & $\operatorname{Mo-2T}\left(C_{1}\right)$ & Mo-3T $\left(C_{s}\right)$ \\
\hline \multirow{3}{*}{ M06-L } & E & -536.04474 & -536.02426 & -536.02360 & -536.01838 & -535.99805 & -535.98708 \\
\hline & $\Delta \mathrm{E}(\Delta \mathrm{H})$ & $0.0(0.0)$ & $12.8(13.5)$ & $13.3(13.5)$ & $16.5(17.0)$ & $29.3(30.5)$ & $36.2(36.8)$ \\
\hline & $\Delta \mathrm{G}_{298}$ & 0.0 & 10.9 & 12.2 & 14.2 & 25.9 & 34.3 \\
\hline \multirow{3}{*}{ BP86 } & E & -536.16875 & -536.15267 & -536.14640 & -536.14416 & -536.12279 & -536.11094 \\
\hline & $\Delta \mathrm{E}(\Delta \mathrm{H})$ & $0.0(0.0)$ & $10.1(10.7)$ & $14.0(14.3)$ & $15.4(15.8)$ & $28.8(30.0)$ & $36.3(36.2)$ \\
\hline & $\Delta \mathrm{G}_{298}$ & 0.0 & 8.1 & 12.9 & 13.1 & 25.4 & 34.3 \\
\hline $\begin{array}{c}\left(\mathrm{C}_{4} \mathrm{H}_{6}\right)_{3} \mathrm{Cr} \\
\left(\mathrm{B} 3 \mathrm{LY} \mathrm{P}^{*}\right)\end{array}$ & $\Delta \mathrm{E}$ & - & 28.5 & 39.5 & 2.3 & 15.3 & 17.4 \\
\hline
\end{tabular}



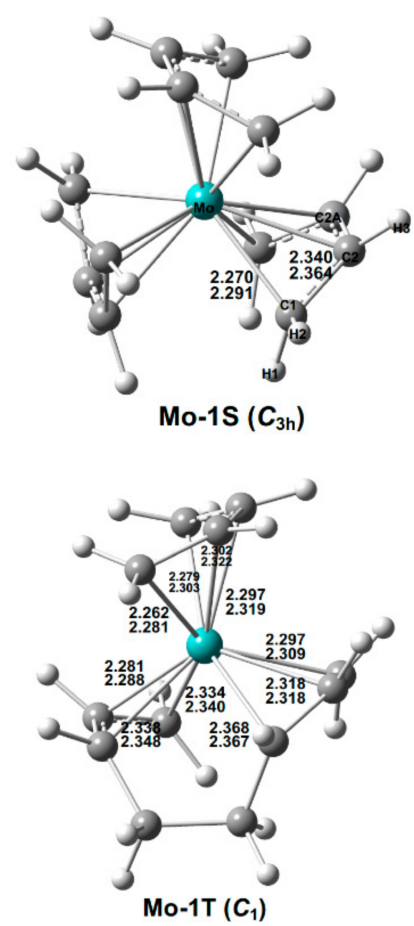
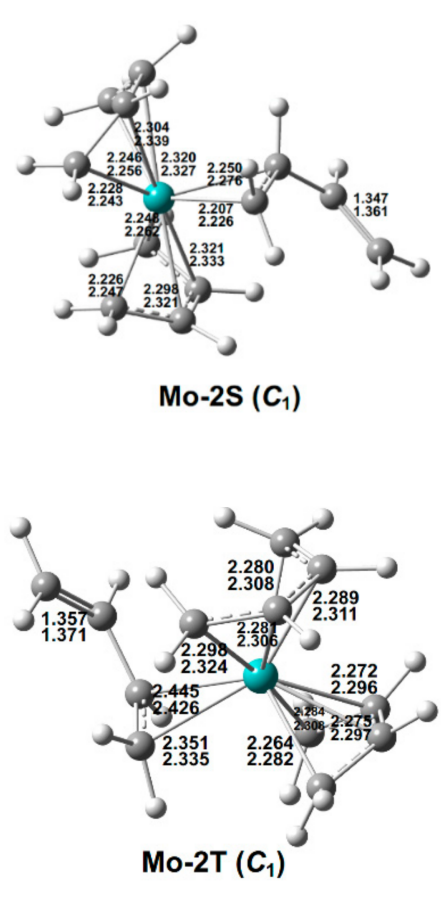

Figure 6. The optimized $\left(\mathrm{C}_{4} \mathrm{H}_{6}\right)_{3}$ Mo structures. The upper and lower distances (in $\AA$ ) are from the M06-L and BP86 methods, respectively.

Table 6. Computed structural parameters of Mo-1S compared to experimental data ${ }^{\text {a }}$.

\begin{tabular}{cccccc}
\hline & M06-L $^{\mathbf{b}}$ & $\mathbf{B P 8 6}^{\mathbf{b}}$ & Expt $^{\mathbf{c}}$ & Expt $^{\mathbf{d}}$ & Expt $^{\mathbf{e}}$ \\
\hline $\mathrm{r}(\mathrm{Mo}-\mathrm{C} 1)$ & 2.270 & 2.291 & $2.29(1)$ & $2.301(8)$ & $2.284(2), 2.273(6)$ \\
$\mathrm{r}(\mathrm{Mo}-\mathrm{C} 2)$ & 2.340 & 2.364 & $2.29(1)$ & $2.317(7)$ & $2.325(2), 2.330(5)$ \\
$\mathrm{r}(\mathrm{C} 1-\mathrm{C} 2)$ & 1.430 & 1.443 & $1.32(2)$ & $1.336(11)$ & $1.414(4), 1.414(7)$ \\
$\mathrm{r}(\mathrm{C} 2-\mathrm{C} 2 \mathrm{~A})$ & 1.402 & 1.414 & $1.55(3)$ & $1.560(18)$ & $1.403(5), 1.388(9)$ \\
$\mathrm{r}(\mathrm{C} 1-\mathrm{H} 1)$ & 1.092 & 1.100 & $1.14(8)$ & & \\
$\mathrm{r}(\mathrm{C} 1-\mathrm{H} 2)$ & 1.088 & 1.097 & $0.96(10)$ & \\
$\mathrm{r}(\mathrm{C} 2-\mathrm{H} 3)$ & 1.088 & 1.098 & $1.12(10)$ & & \\
$\angle \mathrm{C} 1-\mathrm{C} 2-\mathrm{C} 2 \mathrm{~A}$ & 118.9 & 119.1 & $114.84(88), 119.20(15)$ & & \\
$\angle \mathrm{H} 1-\mathrm{C} 1-\mathrm{C} 2$ & 117.2 & 117.6 & $121.99(5.30)$ & \\
$\angle \mathrm{H} 2-\mathrm{C} 1-\mathrm{C} 2$ & 117.5 & 117.1 & $119.10(6.33)$ & & \\
$\angle \mathrm{H} 3-\mathrm{C} 2-\mathrm{C} 2 \mathrm{~A}$ & 119.0 & 118.9 & $125.24(5.32)$ & & \\
$\Sigma \angle(\mathrm{C} 1)^{\mathrm{f}}$ & 348.6 & 348.6 & 349.9 & & \\
\hline
\end{tabular}

a Distances in $\AA$, angles in degrees. ${ }^{\mathrm{b}}$ The present work. ${ }^{\mathrm{c}}$ Skell, P.S.; McGlinchey, M.J. Angew. Chem. Int. Ed. 1975, 14, 195. ${ }^{\mathrm{d}}$ Green, J.C.; Kelly, M.R.; Grebenik, P.D.; Briant, C.E.; McEvoy, N.A.; Mingos, D.M.P. J. Organomet. Chem. 1982, 228, 239. ${ }^{\mathrm{e}}$ Ref. [14]. ${ }^{\mathrm{f}}$ Sum of angles around $\mathrm{C} 1$ (the terminal carbon).

The singlet $\left(\mathrm{C}_{4} \mathrm{H}_{6}\right)_{3}$ Mo structure Mo-2S, with two tetrahapto butadiene ligands and one dihapto butadiene ligand similar to Ru-2S and Tc-1D, is predicted to lie $12.8 \mathrm{kcal} / \mathrm{mol}$ (M06-L) in energy above Mo-1S. The molybdenum atom in Mo-2S has a 16-electron configuration. The singlet Mo-3S, lying $13.3 \mathrm{kcal} / \mathrm{mol}$ (M06-L) in energy above Mo-1S, has a geometry similar to that of Mo-1S, i.e., with three tetrahapto butadiene ligands, but in a different orientation. Thus, in Mo-3S, the molybdenum atom has the favored 18electron configuration.

In contrast to their molybdenum analogs, the singlet $\left(\mathrm{C}_{4} \mathrm{H}_{6}\right)_{3} \mathrm{Cr}$ structures are highenergy structures relative to the triplet and especially the quintet state $\left(\mathrm{C}_{4} \mathrm{H}_{6}\right)_{3} \mathrm{Cr}$ isomers [7]. This difference is another example of the increased ligand field strength of the second-row transition metal complexes relative to the corresponding first-row transition metal complexes, leading to lower-spin state preferred structures for the second-row transition metals. Furthermore, the high energy of singlet $\left(\eta^{4}-\mathrm{C}_{4} \mathrm{H}_{6}\right)_{3} \mathrm{Cr}$ relative to higher-spin state isomers with coupled butadiene ligands as compared with the low energy of its 
molybdenum analog $\left(\eta^{4}-\mathrm{C}_{4} \mathrm{H}_{6}\right)_{3}$ Mo explains why the chromium derivative is unknown but the molybdenum structure is a stable species.

The lowest-energy triplet $\left(\mathrm{C}_{4} \mathrm{H}_{6}\right)_{3}$ Mo structure Mo- $1 \mathrm{~T}$, lying $16.5 \mathrm{kcal} / \mathrm{mol}$ (M06-L) in energy above Mo-1S, has a coupled straight-chain $\eta^{3,3}-\mathrm{C}_{8} \mathrm{H}_{12}$ ligand and a separate $\eta^{4}$ $\mathrm{C}_{4} \mathrm{H}_{6}$ ligand, thereby giving the molybdenum atom a 16-electron configuration consistent with the triplet spin state (Figure 6 and Table 5). The second triplet $\left(\mathrm{C}_{4} \mathrm{H}_{6}\right)_{3}$ Mo structure Mo-2T, lying $29.3 \mathrm{kcal} / \mathrm{mol}$ (M06-L) in energy above Mo-1S, has a ligand arrangement similar to Mo-2S with two tetrahapto $\eta^{4}-\mathrm{C}_{4} \mathrm{H}_{6}$ ligands and one dihapto $\eta^{2}-\mathrm{C}_{4} \mathrm{H}_{6}$ ligand. This gives the molybdenum atom in Mo-2T a 16-electron configuration similar to Mo$2 \mathrm{~S}$. Thus, Mo-2T can be regarded as the high-spin analog of Mo-2S. The significantly higher-energy triplet structure Mo-3T, lying $36.2 \mathrm{kcal} / \mathrm{mol}$ (M06-L) in energy above Mo- $1 \mathrm{~S}$, has a long-chain octahapto $\eta^{3,2,3}-\mathrm{C}_{12} \mathrm{H}_{18}$ ligand, thereby giving the molybdenum atom a 14-electron configuration.

\section{6. $\left(\mathrm{C}_{4} \mathrm{H}_{6}\right)_{3} \mathrm{Nb}$}

Two low-energy doublet $\left(\mathrm{C}_{4} \mathrm{H}_{6}\right)_{3} \mathrm{Nb}$ structures were found (Figure 7 and Table 7). The lowest-energy $\left(\mathrm{C}_{4} \mathrm{H}_{6}\right)_{3} \mathrm{Nb}$ structure $\mathrm{Nb}-1 \mathrm{D}$ has three separate tetrahapto butadiene ligands, thereby giving the niobium atom a 17-electron configuration consistent with the doublet spin state. The second doublet $\left(\mathrm{C}_{4} \mathrm{H}_{6}\right)_{3} \mathrm{Nb}$ structure $\mathrm{Nb}-2 \mathrm{D}$, lying $10.7 \mathrm{kcal} / \mathrm{mol}(\mathrm{M} 06-\mathrm{L})$ in energy above $\mathrm{Nb}-1 \mathrm{D}$, has a coupled long-chain $\eta^{3,2,3}-\mathrm{C}_{12} \mathrm{H}_{18}$ ligand, thereby giving the niobium atom a 13-electron configuration (Figure 7 and Table 7). Quartet $\left(\mathrm{C}_{4} \mathrm{H}_{6}\right)_{3} \mathrm{Nb}$ structures are high-energy structures lying at least $26 \mathrm{kcal} / \mathrm{mol}$ in energy above $\mathrm{Nb}-1 \mathrm{D}$ and thus are not considered in detail. This contrasts with the $\left(\mathrm{C}_{4} \mathrm{H}_{6}\right)_{3} \mathrm{~V}$ system for which quartet structures are the lowest-energy structures.
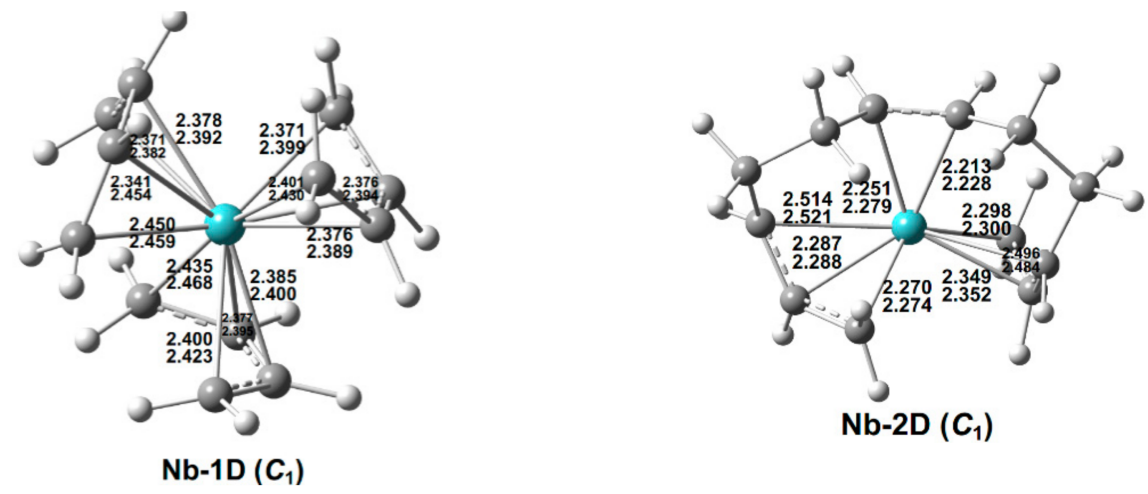

Figure 7. The optimized $\left(\mathrm{C}_{4} \mathrm{H}_{6}\right)_{3} \mathrm{Nb}$ structures. The upper and lower distances (in $\AA$ ) are from the M06-L and BP86 methods, respectively.

Table 7. Total energies with ZPVE corrections ( $\mathrm{E}$ in hartrees), relative energies with ZPVE corrections $(\Delta \mathrm{E}$ in $\mathrm{kcal} / \mathrm{mol})$, relative enthalpies $(\Delta \mathrm{H}$ in $\mathrm{kcal} / \mathrm{mol})$, and relative free energies $\left(\Delta \mathrm{G}_{298} \mathrm{in} \mathrm{kcal} / \mathrm{mol}\right)$ for the $\left(\mathrm{C}_{4} \mathrm{H}_{6}\right)_{3} \mathrm{Nb}$ structures; comparison with the $\left(\mathrm{C}_{4} \mathrm{H}_{6}\right)_{3} \mathrm{~V}$ system [7].

\begin{tabular}{cccc}
\hline & & Nb-1D $\left(\mathbf{C}_{\mathbf{1}}\right)$ & Nb-2D $\left(\mathbf{C}_{\mathbf{1}}\right)$ \\
\hline \multirow{3}{*}{ M06-L } & $\mathrm{E}$ & -524.79243 & -524.77533 \\
& $\Delta \mathrm{E}(\Delta \mathrm{H})$ & $0.0(0.0)$ & $10.7(9.8)$ \\
& $\Delta \mathrm{G}_{298}$ & 0.0 & 11.5 \\
\hline \multirow{2}{*}{ BP86 } & $\mathrm{E}$ & -524.91119 & -524.89914 \\
& $\Delta \mathrm{E}(\Delta \mathrm{H})$ & $0.0(0.0)$ & $7.6(6.7)$ \\
& $\Delta \mathrm{G}_{298}$ & 0.0 & 8.1 \\
\hline$\left(\mathrm{C}_{4} \mathrm{H}_{6}\right)_{3} \mathrm{~V}(\mathrm{~B} 3 \mathrm{LYP})$ & $\Delta \mathrm{E}$ & 9.8 & 4.4 \\
\hline
\end{tabular}




\section{7. $\left(\mathrm{C}_{4} \mathrm{H}_{6}\right)_{3} \mathrm{Zr}$}

Two low-energy $\left(\mathrm{C}_{4} \mathrm{H}_{6}\right)_{3} \mathrm{Zr}$ structures were found (Figure 8 and Table 8). The global minimum by M06-L is the singlet structure $\mathrm{Zr}-1 \mathrm{~S}$. In $\mathrm{Zr}-1 \mathrm{~S}$, the $\mathrm{Zr}-\mathrm{C}$ distances clearly indicate that one of the $\mathrm{C}_{4} \mathrm{H}_{6}$ ligands is tetrahapto, and the remaining two $\mathrm{C}_{4} \mathrm{H}_{6}$ ligands are coupled to form an acyclic $\eta^{3,3}-\mathrm{C}_{8} \mathrm{H}_{12}$ ligand. The other singlet structure $\mathrm{Zr}-2 \mathrm{~S}$, lying $8.9 \mathrm{kcal} / \mathrm{mol}$ (M06-L) in energy above $\mathrm{Zr}-1 \mathrm{~S}$, is shown by its $\mathrm{Zr}-\mathrm{C}$ distances to have three separate tetrahapto $\eta^{4}-\mathrm{C}_{4} \mathrm{H}_{6}$ ligands, thereby giving the zirconium atom a 16-electron configuration. The lowest energy triplet $\left(\mathrm{C}_{4} \mathrm{H}_{6}\right)_{3} \mathrm{Zr}$ structure lies $\sim 27 \mathrm{kcal} / \mathrm{mol}$ in energy above $\mathrm{Zr}-1 \mathrm{~S}$ and therefore is not considered in detail.
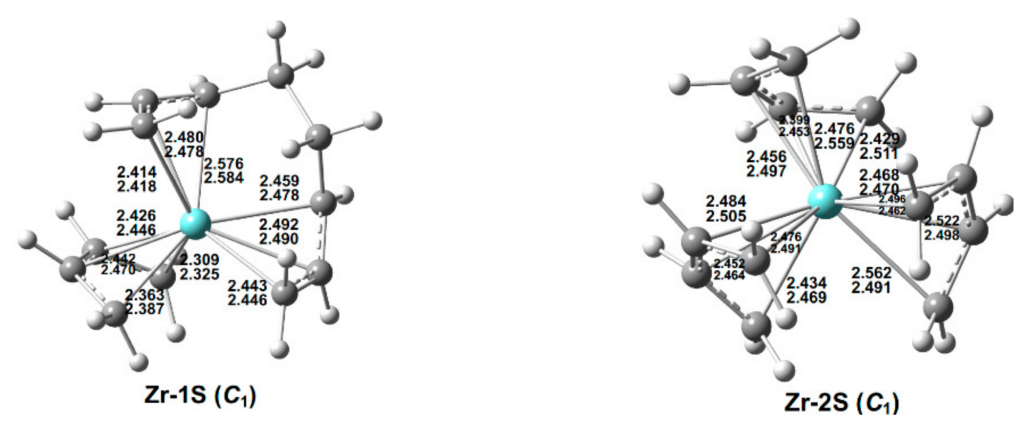

Figure 8. The optimized $\left(\mathrm{C}_{4} \mathrm{H}_{6}\right)_{3} \mathrm{Zr}$ structures. The upper and lower distances (in $\AA$ ) are from the M06-L and BP86 methods, respectively.

Table 8. Total energies with ZPVE correction (E in hartrees), relative energies with ZPVE correction $(\Delta \mathrm{E}$ in $\mathrm{kcal} / \mathrm{mol})$, relative enthalpies $(\Delta \mathrm{H}$ in $\mathrm{kcal} / \mathrm{mol})$, and relative free energies $\left(\Delta \mathrm{G}_{298} \mathrm{in} \mathrm{kcal} / \mathrm{mol}\right)$ for the $\left(\mathrm{C}_{4} \mathrm{H}_{6}\right)_{3} \mathrm{Zr}$ structures.

\begin{tabular}{cccc}
\hline & & Zr-1S $\left(\mathbf{C}_{\mathbf{1}}\right)$ & Zr-2S $\left(\mathbf{C}_{\mathbf{1}}\right)$ \\
\hline \multirow{3}{*}{ M06-L } & $\mathrm{E}$ & -514.89112 & -514.87692 \\
& $\Delta \mathrm{E}(\Delta \mathrm{H})$ & $0.0(0.0)$ & $8.9(9.4)$ \\
& $\Delta \mathrm{G}_{298}$ & 0.0 & 8.5 \\
\hline \multirow{2}{*}{ BP86 } & $\mathrm{E}$ & -515.00107 & -514.98811 \\
& $\Delta \mathrm{E}(\Delta \mathrm{H})$ & $0.0(0.0)$ & $8.1(8.5)$ \\
& $\Delta \mathrm{G}_{298}$ & 0.0 & 8.1 \\
\hline$\left(\mathrm{C}_{4} \mathrm{H}_{6}\right)_{3} \mathrm{Ti}(\mathrm{B} 3 \mathrm{LYP})$ & $\Delta \mathrm{E}$ & 0.0 & 15.5 \\
\hline
\end{tabular}

\section{Summary}

The lowest-energy $\left(\mathrm{C}_{4} \mathrm{H}_{6}\right)_{3} \mathrm{M}$ structures for the second-row transition metals from zirconium to palladium are all low-spin singlet and doublet structures, in contrast to the corresponding derivatives of the first-row transition metals. This is a reflection of the higher ligand field strength of the second-row transition metal derivatives relative to the analogous first-row transition metal derivatives.

In addition to the preference for low-spin structures, the energetically preferred structure types for the second-row transition metal $\left(\mathrm{C}_{4} \mathrm{H}_{6}\right)_{3} \mathrm{M}$ derivatives are found to depend on the electronic requirements of the central metal atom to attain the favored 18-electron configuration. Thus, attaining the 18-electron configuration for the late second-row transition metals from palladium to ruthenium leaves one or two uncomplexed $\mathrm{C}=\mathrm{C}$ double bonds in the set of three surrounding butadiene ligands. In such complexes, the uncomplexed $\mathrm{C}=\mathrm{C}$ double bonds provide reactive sites to couple with adjacent butadiene ligands to form structures with an open-chain $\mathrm{C}_{12} \mathrm{H}_{18}$ ligand. As a result, the three butadiene ligands in the lowest-energy $\left(\mathrm{C}_{4} \mathrm{H}_{6}\right)_{3} \mathrm{M}$ structures of the late second-row transition metals couple to form a $\mathrm{C}_{12} \mathrm{H}_{18}$ ligand that binds to the central metal atom as a hexahapto ligand for $\mathrm{M}=\mathrm{Pd}$ but as an octahapto ligand for $\mathrm{M}=\mathrm{Rh}$ and $\mathrm{Ru}$. Thus, the four lowest-energy $\left(\mathrm{C}_{12} \mathrm{H}_{18}\right) \mathrm{Pd}$ structures resemble their nickel analogs with similar relative energies. However, attaining 
or even approaching the favored 18-electron configuration for $\left(\mathrm{C}_{4} \mathrm{H}_{6}\right)_{3} \mathrm{M}$ complexes of the early transition metals from zirconium to technetium requires complexation of all six $\mathrm{C}=\mathrm{C}$ double bonds of three surrounding butadiene ligands. As a result, the lowest-energy $\left(\mathrm{C}_{4} \mathrm{H}_{6}\right)_{3} \mathrm{M}$ structures have three tetrahapto butadiene ligands for $\mathrm{M}=\mathrm{Zr}, \mathrm{Nb}$, and $\mathrm{Mo}$ or two tetrahapto butadiene ligands and one dihapto butadiene ligand for $\mathrm{M}=\mathrm{Tc}$. The low energy of the experimentally known singlet $\left(\mathrm{C}_{4} \mathrm{H}_{6}\right)_{3}$ Mo structure contrasts with the very high energy of its experimentally unknown singlet chromium $\left(\mathrm{C}_{4} \mathrm{H}_{6}\right)_{3} \mathrm{Cr}$ analog relative to quintet $\left(\mathrm{C}_{12} \mathrm{H}_{18}\right) \mathrm{Cr}$ isomers with an open-chain $\mathrm{C}_{12} \mathrm{H}_{18}$ ligand. The $\left(\mathrm{C}_{4} \mathrm{H}_{6}\right)_{3} \mathrm{M}$ complexes studied in this work are potentially accessible by reactions of the metal vapors with butadiene under suitable conditions similar to the reported synthesis of the molybdenum derivative $\left(\mathrm{C}_{4} \mathrm{H}_{6}\right)_{3}$ Mo.

Supplementary Materials: The following are available online, Tables S1-S25: Atomic coordinates of the optimized structures for the $\left(\mathrm{C}_{4} \mathrm{H}_{6}\right)_{3} \mathrm{M}(\mathrm{M}=\mathrm{Pd}, \mathrm{Rh}, \mathrm{Ru}, \mathrm{Tc}, \mathrm{Mo}, \mathrm{Nb}, \mathrm{Zr})$ complexes.

Author Contributions: Y.Z., Q.C., M.H., Z.Z. performed the calculations to generate the data; X.F. supervized the group at Changzhou University and provided an initial summary of the data; Y.X. did the initial editing of the material provided by X.F.; R.B.K. suggested the original project, wrote the Introduction, and edited the remainder of the manuscript; H.F.S. reviewed and edited the final version of the manuscript. All authors have read and agreed to the published version of the manuscript.

Funding: National Science Foundation (Grant No. CHE-1661604).

Institutional Review Board Statement: Not applicable.

Informed Consent Statement: Not applicable.

Data Availability Statement: Not applicable.

Acknowledgments: This work was supported by the Jiangsu Key Laboratory of Advanced Catalytic Materials and Technology, Changzhou University in China, Advanced Catalysis and Green Manufacturing Collaborative Innovation Center, Changzhou University in China. Research at The University of Georgia was supported by the U.S. National Science Foundation (grant No. CHE-1661604).

Conflicts of Interest: There authors declare no conflict of interest.

Sample Availability: Not applicable.

\section{References}

1. Reihlen, O.; Gruhl, A.; Hessling, G.; Pfrengle, O. Über Carbonyle und Nitrosyle. IV. Liebigs Ann. Chem. 1930, 482, 161-182. [CrossRef]

2. Hallam, B.F.; Pauson, P.L. Metal derivatives of conjugated dienes. Part I. Butadiene-and cyclohexadiene-iron tricarbonyls. J. Chem. Soc. 1958, 642-645. [CrossRef]

3. Kealy, T.J.; Pauson, P.L. A new type of organo-iron compound. Nature 1951, 168, 1039-1040. [CrossRef]

4. Miller, S.A.; Tebboth, J.A.; Tremaine, J.F. Dicyclopentadienyliron. J. Chem. Soc. 1952, 3, 632-635. [CrossRef]

5. Mills, O.S.; Robinson, G. Studies of some carbon compounds of the transition metals. IV. The structure of butadiene iron tricarbonyl. Acta Crystallogr. 1963, 16, 758-761. [CrossRef]

6. Brauer, D.J.; Krüger, C. The three-dimensional structure of trans-trans-trans-1,5,9-cyclododecatrienenickel. J. Organomet. Chem. 1972, 44, 397-402. [CrossRef]

7. Fan, Q.; Li, H.; Fu, J.; Fan, Z.; Xu, Y.; Feng, H.; Xie, Y.; King, R.B.; Schaefer, H.F. Tris(butadiene) metal complexes of the first row transition metals versus coupling of butadiene to eight and twelve-carbon hydrocarbon chains. J. Phys. Chem. A 2019, 123, 5542-5554. [CrossRef]

8. Jolly, P.W.; Mynott, R.; Salz, R. Bis( $\eta^{4}$-2,3-dimethyl-1,3-butadiene) nickel. J. Organomet. Chem. 1980, 184, C49-C52. [CrossRef]

9. Cloke, F.G.N.; McCamley, A. Butadiene sandwich compounds-Synthesis of bis( $\eta$-1,4-di-tert-butylbuta-1,3,-diene) complexes of titanium and vanadium. Chem. Commun. 1991, 1470-1471. [CrossRef]

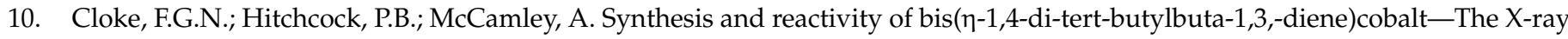
crystal structure of the anionic butadiene sandwich complex $\left[\mathrm{K}(18-\mathrm{crown}-6)(\mathrm{thf})_{2}\right]\left[\mathrm{Co}\left(\mathrm{\eta}-\mathrm{C}_{4} \mathrm{H}_{4} \mathrm{Bu}^{\mathrm{t}}{ }_{2}\right)_{2}\right]$. Chem. Commun. 1993, 248-250. [CrossRef]

11. Cloke, F.G.N.; Gardiner, M.G.; Raston, C.L.; Simpson, S.J. Bis\{1,4-bis(trimethylsilyl) buta-1,3-diene\}cobalt: Synthesis and molecular structure. J. Organomet. Chem. 1996, 507, 245-248. [CrossRef]

12. Skell, P.S.; VanDam, E.M.; Simon, M.P. Reactions of tungsten and molybdenum atoms with 1,3-butadiene. Tris(butadiene)tungsten and molybdenum. J. Am. Chem. Soc. 1974, 96, 626-627. [CrossRef] 
13. Gausing, W.; Wilke, G. Reduktive synthese und reaktivität von Tris (butadien) molybdän und wolfram. Angew. Chem. 1981, 93, 201-202. [CrossRef]

14. Kaupp, M.; Kopf, T.; Murso, A.; Stalke, D.; Strohmann, C.; Hanks, J.R.; Cloke, F.G.N.; Hitchcock, P.B. Trigonal prismatic structure of tris(butadiene)molybdenum and related complexes revisited: Diolefin or metallacyclopentene coordination? Organometallics 2002, 21, 5021-5028. [CrossRef]

15. Stephan, G.C.; Naether, C.; Peters, G.; Tuczek, F. Molybdenum 17- and 18-electron bis and tris(butadiene) complexes: Electronic structures, spectroscopic properties, and oxidative ligand substitution reactions. Inorg. Chem. 2013, 52, 5931-5942. [CrossRef]

16. Bollermann, T.; Cadenbach, T.; Gemel, C.; Freitag, K.; Molon, M.; Gwildies, V.; Fischer, R.A. Homoleptic hexa and penta gallylene coordinated complexes of molybdenum and rhodium. Inorg. Chem. 2011, 50, 5808-5814. [CrossRef]

17. Ziegler, T.; Autschbach, J. Theoretical methods of potential use for studies of inorganic reaction mechanisms. Chem. Rev. 2005, 105, 2695-2722. [CrossRef]

18. Bühl, M.; Kabrede, H. Geometries of transition-metal complexes from density-functional theory. J. Chem. Theory Comput. 2006, 2, 1282-1290. [CrossRef]

19. Brynda, M.; Gagliardi, L.; Widmark, P.O.; Power, P.P.; Roos, B.O. A quantum chemical study of the quintuple bond between two chromium centers in [PhCrCrPh]: Trans-Bent versus linear geometry. Angew. Chem. Int. Ed. 2006, 45, 3804-3807. [CrossRef]

20. Sieffert, N.; Bühl, M. Hydrogen generation from alcohols catalyzed by ruthenium-triphenylphosphine complexes: Multiple reaction pathways. J. Am. Chem. Soc. 2010, 132, 8056-8070. [CrossRef]

21. Schyman, P.; Lai, W.; Chen, H.; Wang, Y.; Shaik, S. The directive of the protein: How does cytochrome P450 select the mechanism of dopamine formation? J. Am. Chem. Soc. 2011, 133, 7977-7984. [CrossRef] [PubMed]

22. Adams, R.D.; Pearl, W.C.; Wong, Y.O.; Zhang, Q.; Hall, M.B.; Walensky, J.R. Tetrarhena-heterocycle from the palladium-catalyzed dimerization of $\operatorname{Re}_{2}(\mathrm{CO})_{8}\left(\mu-\mathrm{SbPh}_{2}\right)(\mu-\mathrm{H})$ exhibits an unusual host-guest behavior. J. Am. Chem. Soc. 2011, 133, 12994-12997. [CrossRef] [PubMed]

23. Lonsdale, R.; Olah, J.; Mulholland, A.J.; Harvey, J.N. Does compound I vary significantly between isoforms of cytochrome P450? J. Am. Chem. Soc. 2011, 133, 15464-15474. [CrossRef] [PubMed]

24. Zhao, Y.; Truhlar, D.G. A new local density functional for main-group thermochemistry, transition metal bonding, thermochemical kinetics, and noncovalent interactions. J. Chem. Phys. 2006, 125, 194101. [CrossRef] [PubMed]

25. Becke, A.D. Density functional exchange-energy approximation with correct asymptotic behavior. Phys. Rev. A 1988, 38, 3098-3100. [CrossRef]

26. Perdew, J.P. Density-Functional approximation for the correlation energy of the inhomogeneous electron gas. Phys. Rev. B 1986, 33, 8822-8824. [CrossRef]

27. Becke, A.D. Density functional thermochemistry. III. The role of exact exchange. J. Chem. Phys. 1993, 98, 5648-5652. [CrossRef]

28. Lee, C.; Yang, W.; Parr, R.G. Development of the Colle-Salvetti correlation-energy formula into a functional of the electron density. Phys. Rev. B 1988, 37, 785-789. [CrossRef]

29. Reiher, M.; Salomon, O.; Hess, B.A. Reparameterization of hybrid functionals based on energy differences of states of different multiplicity. Theor. Chem. Acc. 2001, 107, 48-55. [CrossRef]

30. Dolg, M.; Stoll, H.; Preuss, H. A combination of quasi-relativistic pseudopotential and ligand-field calculations for lanthanoid compounds. Theor. Chim. Acta 1993, 85, 441-445. [CrossRef]

31. Bergner, A.; Dolg, M.; Kuechle, W.; Stoll, H.; Preuss, H. Ab-initio energy-adjusted pseudopotentials for elements of groups 13-17. Mol. Phys. 1993, 80, 1431-1441. [CrossRef]

32. Dunning, T.H. Gaussian basis functions for use in molecular calculations. I. Contraction of (9s5p) atomic basis sets for the first-row atoms. J. Chem. Phys. 1970, 53, 2823-2833. [CrossRef]

33. Frisch, M.J.; Trucks, G.W.; Schlegel, H.B.; Scuseria, G.E.; Robb, M.A.; Cheeseman, J.R.; Scalmani, G.; Barone, V.; Mennucci, B.; Petersson, G.A.; et al. Revision, D.01; Gaussian Inc.: Wallingford, CT, USA, 2009.

34. Papas, B.N.; Schaefer, H.F. Concerning the precision of standard density functional programs: Gaussian, Molpro, NWChem, Q-Chem, and Gamess. J. Mol. Struct. THEOCHEM 2006, 768, 175-181. [CrossRef] 